\title{
Bola 反离子诱导的高粘弹十六烷基硫酸钠蠕虫胶束溶液
}

\author{
赵剑曦* 杨铎平 \\ (福州大学化学化工学院应用化学系胶体与界面化学研究所, 福州 350108)
}

\begin{abstract}
摘要: 利用稳态和频率扫描研究了十六烷基硫酸钠(SHS)与 Bola 盐( $N, N^{\prime}$-双乙基二甲基- $\alpha, \omega$-乙烷溴化铵 (Bola2Et)或 $N, N^{\prime}$-三甲基- $a, \omega$-丁 烷溴化铵 (Bola4))混合体系的流变行为. 实验结果表明两个体系均在 $45^{\circ} \mathrm{C}$ 时 形成了长蠕虫胶束, 溶液呈现出高粘弹性, 尤其是 SHS/Bola2Et 溶液表现出很高的弹性, 零剪接粘度高达 $2520 \mathrm{~Pa} \cdot \mathrm{s}$, 表观上呈现胶状. 这些结果归因于在Bola 反离子诱导下, 表面活性剂 SHS 与 Bola 反离子形成了 静电吸引的 2:1 结构复合物. 由于这两个Bola反离子的联接链长度均短于季铵离子的静电平衡距离, 因此形成 的复合物在形状上有利于蠕虫胶束生成. 作为对比, 添加简单的四甲基铵反离子无法诱导 SHS 形成蠕虫胶束, 溶液仅呈现低粘度.
\end{abstract}

关键词: 阴离子表面活性剂; Bola 反离子; 蠕虫状胶束; 高粘弹性

中图分类号: 0646

\section{Highly Viscoelastic Worm-Like Micelle Solution of Sodium Hexadecyl Sulfate Induced by Bolaform Counterions}

\author{
ZHAO Jian-Xi* YANG Duo-Ping \\ (Institute of Colloid and Interface Chemistry, Department of Applied Chemistry, College of Chemistry and Chemical Engineering, \\ Fuzhou University, Fuzhou 350108, P. R. China)
}

\begin{abstract}
The rheological behaviors of mixed aqueous solutions of sodium hexadecyl sulfate (SHS) and a bolaform salt, either $N, N^{\prime}$-ethanediyl- $\alpha, \omega$-bis(ethyldimethylammonium bromide) (Bola2Et) or $N, N^{\prime}$ propanediyl- $\alpha, \omega$-bis(trimethylammonium bromide) (Bola4), were investigated by steady-state and frequencysweep measurements. The results showed that long worm-like micelles were formed in both systems at $45^{\circ} \mathrm{C}$, and the solutions exhibited high viscoelasticities, especially the SHS/Bola2Et system in which the solution had very high elasticity. The zero-shear viscosity of SHS/Bola2Et was as high as $2520 \mathrm{~Pa} \cdot \mathrm{s}$, and the system was gel-like. These results were attributed to the formation of 2:1 complexes by electrostatic attraction. Since the spacers of both Bola counterions were shorter than the distance between quaternary ammonium ions under electrostatic equilibrium, the generated complex in shape favored formation of worm-like micelles. In comparison, it was difficult to induce SHS to form worm-like micelles by the addition of tetramethylammonium counterions, and the solution exhibited low viscosity.
\end{abstract}

Key Words: Anionic surfactant; Bola-counterion; Worm-like micelle; High viscoelasticity

\section{Introduction}

The worm-like micelle is a heavily investigated aspect of the surfactant solution behavior from both theoretical and applica- tion viewpoints. ${ }^{1-3}$ So far, most of the worm-like micelles are formed by cationic cetyltrimethylammonium halides $\left(\mathrm{C}_{16} \mathrm{TAX}\right)$ and their derivatives under the assistance of salts such as salicy-

Received: November 16, 2011; Revised: February 1, 2012; Published on Web: February 21, 2012.

"Corresponding author. Email: jxzhao.colloid@fzu.edu.cn; Tel: +86-591-22866338.

The project was supported by the National Natural Science Foundation of China (20673021, 20873024) and Natural Science Foundation of Fujian Province, China (2010J01038).

国家自然科学基金(20673021, 20873024)及福建省自然科学基金(2010J01038)资助项目

(C) Editorial office of Acta Physico-Chimica Sinica 
late, tosylate, or dichlorobenzoate, etc. ${ }^{4-11}$ Comparatively, anionic worm-like micelles could offer advantages over cationic counterparts in many applications, including enhanced oil recovery. ${ }^{12}$ However, the addition of salt often induced the precipitate of anionic single-chain surfactants. In a few successful systems, the anionic worm-like micelles were not as long as cationic ones. ${ }^{13-15}$ For instance, the worm-like micelles formed by sodium dodecyl trioxyethylene sulfate (SDES) in the presence of tri-valence counterion $\mathrm{Al}^{3+}$ were only $100-200 \mathrm{~nm}$ in average length. ${ }^{14(\mathrm{a}-\mathrm{c})}$ On the contrary, the cationic worm-like micelles often attained the contour length of several micrometers. ${ }^{1,2}$ This made the viscosity of anionic worm-like micelle solutions considerably low even at high surfactant concentrations.

Gemini surfactant is made up of two amphiphilic moieties connected at the level of the head groups or very close to the head groups by a spacer group. ${ }^{16}$ When the spacer is very short such as being made of two or three methylene groups, the gemini surfactant has a columnar-like molecular geometry and thus can spontaneously form worm-like micelles without the assistance of salt. Typical cases were cationic quaternary ammonium gemini surfactants, ethanediyl- $\alpha, \omega$-bis(dimethylalkylammonium bromide) (generally referred to as $m-2-n$, where $m$ and $n$ expressed the number of carbon atoms in each alkyl tail). ${ }^{17-19} \mathrm{Il}-$ luminated by these results, we attempted to construct a pseudo complex through a bolaform ion attracting two oppositely charged single-chain surfactants in which the bolaform ion is expected to play a role of spacer analogous to that in geminis.

Bolaform counterion has separate charge controlled by a spacer. Early investigations performed by Moroi et al have revealed that the aggregation of alkane-1-sulfonates in aqueous solution depended upon the length of the spacer of bolaform counterions, 1,1'-(1, $\omega$-alkanediyl)bispyridinium, including the critical micelle concentration $(\mathrm{cmc})^{20,21}$ and the micelle aggregation number. ${ }^{22}$ Very recently, we ${ }^{23}$ studied the influence of bolaform salts in aqueous subphase on the Langmuir monolayer behavior of sodium hexadecyl sulfate (SHS). In this paper, we report the rheological behavior of SHS induced by bolaform salt, ethanediyl- $\alpha, \omega$-bis(ethyldimethylammonium bromide) (Bola2Et) or propanediyl- $\alpha, \omega$-bis(trimethylammonium bromide) (Bola4). The effect of corresponding single salt, tetramethylammonium bromide (TMAB), was examined for comparison.

\section{Experimental}

\subsection{Materials}

The compounds used, including their chemical structures and abbreviations, are listed in Table 1. TMAB was purchased from Acros (USA) and used as received. The others were synthesized in our laboratory and confirmed by NMR and element analysis, which were described in detail elsewhere. ${ }^{23}$

\subsection{Methods}

Solutions were prepared at $45{ }^{\circ} \mathrm{C}$ due to high Krafft temperature $\left(36^{\circ} \mathrm{C}\right)$ of SHS. ${ }^{24}$ The addition of salts was $64 \mathrm{mmol} \cdot \mathrm{L}^{-1}$ for
Table 1 Molecular structures and abbreviations of the compounds

\begin{tabular}{ccc}
\hline Structure & Compound & Abbreviation \\
\hline sodium hexadecyl sulfate & SHS \\
$\begin{array}{c}N, N^{\prime} \text {-ethanediyl } \alpha, \omega- \\
\text { bis(ethyldimethylammonium } \\
\text { bromide) } \\
N, N^{\prime} \text {-propanediyl- } \alpha, \omega- \\
\text { bis(trimethylammonium } \\
\text { bromide) }\end{array}$ & Bola2Et \\
\hline
\end{tabular}

single-valence TMAB and $32 \mathrm{mmol} \cdot \mathrm{L}^{-1}$ for double-valence Bola2Et or Bola4, respectively, so as to keep identical ionic strength in the solution. The water used was Milli-Q grade with a resistivity of $18 \mathrm{M} \Omega \cdot \mathrm{cm}$.

Rheological measurements were performed on an AR2000ex (USA) stress controlled rheometer with cone-plate sensor. The cone is made of standard ETC steel with the diameter of $40 \mathrm{~mm}$ and cone angle of $2^{\circ}$. The gap between the center of the cone and plate is $50 \mu \mathrm{m}$. The temperature was kept at $45^{\circ} \mathrm{C}$ throughout the experiments. Each sample was kept for $10 \mathrm{~min}$ on the plate to reach the equilibrium prior to conducting experiments. Dynamic frequency-sweep measurements were performed in the linear viscoelastic region of the samples as determined previously by dynamic strain sweep measurements.

\section{Results and discussion 3.1 Steady-state viscosity}

Fig. 1 shows the plots of steady-state viscosity of the solutions versus shear rate, in which SHS alone only has very low viscosity of $\sim 1 \mathrm{mPa} \cdot \mathrm{s}$. Upon the addition of $64 \mathrm{mmol} \cdot \mathrm{L}^{-1}$ $\mathrm{TMAB}$, the viscosity increases to $83 \mathrm{mPa} \cdot \mathrm{s}$ and the curve almost keeps horizontal over the shear range examined. In the case of $32 \mathrm{mmol} \cdot \mathrm{L}^{-1}$ Bola2Et, however, a low shear Newtonian plateau followed by clearly shear thinning at higher shear rates is seen, which is typical behavior of viscoelastic worm-

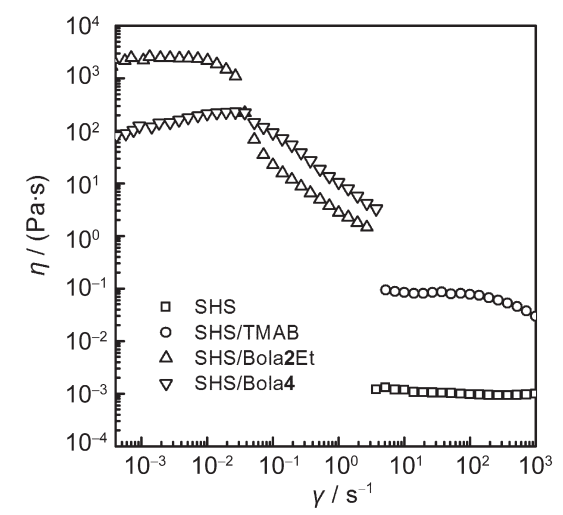

Fig.1 Plots of viscosity versus steady shear rate for the aqueous solutions of SHS $\left(200 \mathrm{mmol} \cdot \mathrm{L}^{-1}\right)$ in the presence of $64 \mathrm{mmol} \cdot \mathrm{L}^{-1}$ TMAB or $32 \mathrm{mmol} \cdot \mathrm{L}^{-1}$ bolaform salts at $45^{\circ} \mathrm{C}$

For comparison the plot of SHS alone is also shown. 
like micellar solution as reported in literature. ${ }^{25-27}$ The zeroshear viscosity $\left(\eta_{0}\right)$ can be obtained according to the Carreau model and is as high as $2520 \mathrm{~Pa} \cdot \mathrm{s}$. This value is far higher than all the viscosities yielded by traditional anionic surfactants up to now, for instance, $\eta_{0}$ of SDES in the presence of tri-valence counterion $\mathrm{Al}^{3+}$ is only $1.9-4.8 \mathrm{~Pa} \cdot \mathrm{s},{ }^{14(a, b)}$ while $\eta_{0}$ of sodium oleate $/ \mathrm{Et}_{3} \mathrm{NHCl}$ also just attains $30 \mathrm{~Pa} \cdot \mathrm{s} .{ }^{15}$ It is worth to mention that the present high viscosity yields at relatively high temperature $\left(45^{\circ} \mathrm{C}\right)$, which is generally rather difficult since the solution viscosity evidently falls with increasing temperature. ${ }^{28}$ This result indicates that SHS may form long worm-like micelles at $45^{\circ} \mathrm{C}$. Compared with TMAB-adding, the Bola2Et system has identical ionic strength and therefore the bolaform counterions certainly play a dominant role.

Our previous investigation ${ }^{23}$ revealed that electrostatic attraction can effectively occur between SHS and bolaform counterions and thus the monolayer behavior of SHS was controlled by the bola-counterions in water subphase, strongly depending on the length of the spacer of bola-counterions. For the present system, the bola-counterions should also play the similar effect, perhaps leading to the formation of the complexes having a pseudo gemini structure in the aggregates, i.e., being made up of two SHS ions and one counterion by electrostatic attraction. Here we try to discuss possible shape of the complex. The molecular geometry of surfactant was often characterized as a dimensionless packing parameter $P$, by which Israelachvilii ${ }^{29}$ predicted that cylindrical micelles are favored when $1 / 3<P<$ $1 / 2$. It was known $P=v /(a l)$, where $v$ is the hydrocarbon chain volume, $a$ is the optimum head-group area per molecule, and $l$ is the hydrocarbon chain length. For the complex of SHS/ Bola2Et, the area of gemini surfactant, ethanediyl- $\alpha, \omega$-bis(dodecyldimethylammonium bromide), at air/water interface is used approximately as $a$, which is about $0.7-0.8 \mathrm{~nm}^{2} \cdot{ }^{30,31}$ Both $v$ and $l$ can be simply calculated by Tanford formulas. ${ }^{32}$ Thus, the $P$ of complex is $0.53-0.60$, which means that the complex may be columnar-like in geometric shape and agrees with a short spacer of Bola2Et only with two methylene groups. As a rough estimation, this value is rather satisfactory for interpreting the formation of worm-like micelles under the inducement

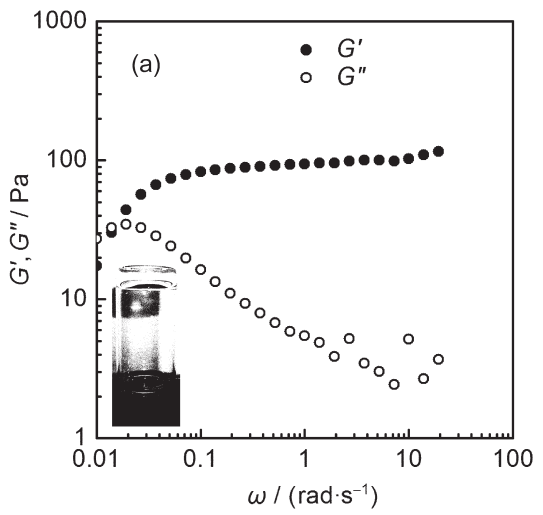

of Bola2Et. As revealed in the mechanism of worm-like micelle formation, a columnar-like molecular geometry for amphiphiles is essential condition, which not only favors to construct the aggregates with low surface curvature but also creates the energy difference between the cylindrical body and the hemispherical endcaps, the latter has been known as the driving force for the micellar growth. ${ }^{1-3}$ This inference may be supported by the cases of gemini surfactants $12-2-16$ or 14-2-18 in constructing worm-like micelles. The both geminis had a short spacer with two methylene groups and their worm-like micellar solutions also showed the viscosity over $2000 \mathrm{~Pa} \cdot \mathrm{s}^{19}$

Another strong support comes from the case of SHS/Bola4. Compared with Bola2Et, Bola4 has a longer spacer (made up of 4 methylene groups) and thus the effective shape of SHS/ Bola4 complex, if formed, may be not as ideal as SHS/Bola2Et for constructing worm-like micelles. The corresponding viscosity indeed sharply falls to $183 \mathrm{~Pa} \cdot \mathrm{s}$ (Fig.1). This indicates that the length of bolaform counterions controls the aggregation of SHS. Even if SHS/Bola4 system has a relatively low viscosity, the value of $183 \mathrm{~Pa} \cdot \mathrm{s}$ has exceeded those yielded by traditional anionic surfactants as mentioned above, showing the charms of gemini-like molecular geometry.

\subsection{Viscoelastic spectra}

Fig.2 shows the dynamic rheological spectra of SHS/ Bola2Et and SHS/Bola4 systems. For SHS/Bola2Et, elastic modulus $\left(G^{\prime}\right)$ exceeds viscous modulus $\left(G^{\prime \prime}\right)$ almost at all the frequencies examined, which is consistent with the high viscosity discussed in the above section. The SHS/Bola4 system exhibits the behavior close to Maxwell fluid over low and medium frequency ranges, ${ }^{33}$ whose Cole-Cole plot is shown in Fig.3. The Maxwell model with a single stress relaxation time $\left(\tau_{\mathrm{R}}\right)$ can be expressed as follows: $:^{33,34}$

$$
\begin{aligned}
G^{\prime} & =\frac{\left(\omega \tau_{\mathrm{R}}\right)^{2}}{1+\left(\omega \tau_{\mathrm{R}}\right)^{2}} G_{\infty}^{\prime} \\
G^{\prime \prime} & =\frac{\omega \tau_{\mathrm{R}}}{1+\left(\omega \tau_{\mathrm{R}}\right)^{2}} G_{\infty}^{\prime}
\end{aligned}
$$

where $G_{\infty}^{\prime}$ is plateau modulus at high frequencies. According to the model, fitting result is shown as solid line in Fig.2, which follows the experimental data at low and medium frequencies.

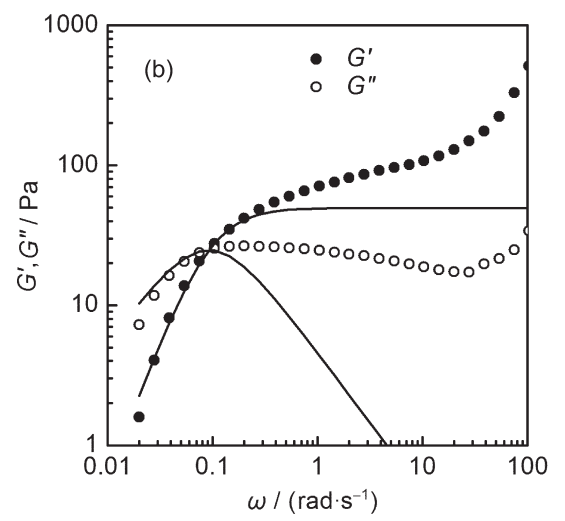

Fig.2 Dynamic rheological spectra of the aqueous solutions of SHS $\left(200 \mathrm{mmol} \cdot \mathrm{L}^{-1}\right)$ in the presence of $32 \mathrm{mmol} \cdot \mathrm{L}^{-1} \mathrm{bolaform} \mathrm{salts} \mathrm{at} 45^{\circ} \mathrm{C}$ (a) SHS/Bola2Et, (b) SHS/Bola4. Inset in figure (a) shows the appearance of the sample. 


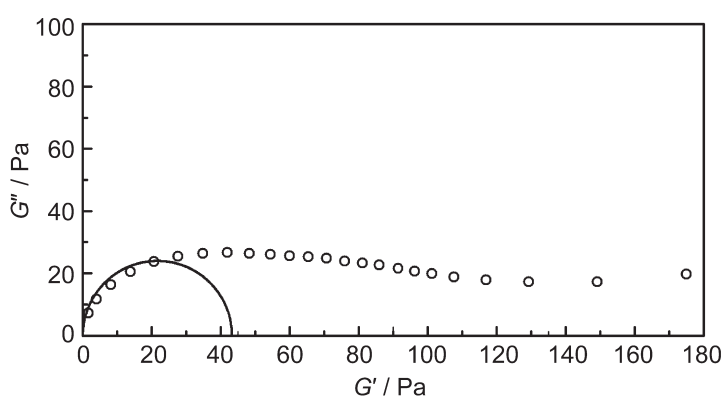

Fig.3 Cole-Cole plot of the SHS/Bola4 system The solid line stands for the best fit to the Maxwell model.

The deviation of the $G_{\infty}^{\prime \prime}$ from the model at high $\omega$ region is also a characteristic of the worm-like micelles, ${ }^{35}$ which corresponds to the fact that worm-like micelles are in a dynamic equilibrium and there is a rapid breaking and recombination process. ${ }^{17}$

From the viscoelastic spectrum of SHS/Bola4, the relaxation time, $\tau_{\mathrm{R}}$, is estimated as $\omega_{\mathrm{c}}^{-1}$, where $\omega_{\mathrm{c}}$ is the frequency at which two moduli are equal. ${ }^{36}$ In surfactant systems where the $G^{\prime}$ does not give a constant limiting value, the $G_{\infty}^{\prime}$ may be estimated from the modulus value at $\omega_{\mathrm{c}}$, using the relation $G_{\infty}^{\prime}=2 G_{\max }^{\prime \prime}$, where $G_{\max }^{\prime \prime}$ is the viscosity modulus at shear frequency $\omega_{\mathrm{c}}{ }^{36}$ Thus the present $\tau_{\mathrm{R}}$ and $G_{\infty}^{\prime}$ are $10.9 \mathrm{~s}$ and $49.6 \mathrm{~Pa}$.

Granek and Cates $^{37}$ described the dynamics of the viscoelastic micellar system by combining the reptation model of polymer dynamics with the effect of reversible scission on viscoelastic properties. The model involves two time scales of stress relaxation, namely, reptation time $\left(\tau_{\text {rep }}\right)$, which corresponds to the curvilinear diffusion of a chain of the mean length along its own contour, and breaking time $\left(\tau_{\mathrm{b}}\right)$. When breaking occurs over the time scale of reptation $\left(\tau_{\mathrm{b}}<<\tau_{\text {rep }}\right)$, as in a typical wormlike micellar system, the chain undergoes many breakages and recombinations before a chain segment relaxes by reptation. The stress relaxation is characterized by a new time scale given by $\tau_{\mathrm{R}}=\left(\tau_{\mathrm{b}} \tau_{\mathrm{rep}}\right)^{1 / 2}$, and the solution behaves as a Maxwell fluid with single relaxation time, $\tau_{\mathrm{R}}$. The average scission time for the micelle, $\tau_{\mathrm{b}}$, is approximately equal to the inverse of $\omega$ corresponding to the minimum of $G_{\min }^{\prime \prime}$ in the high-frequency region. For the SHS/Bola4 solution, the estimated value of $\tau_{\mathrm{b}}$ is 0.036 s. The value allows us to estimate $\tau_{\text {rep }} \sim 3360 \mathrm{~s}$, using the $\tau_{\mathrm{R}}$ data. The result satisfies the expectation of $\tau_{\mathrm{b}}<<\tau_{\text {rep. }}$.

In principle, the contour length of worm-like micelle, $L$, can be estimated from viscoelastic spectrum by the following relation: ${ }^{33}$

$$
L \approx l_{\mathrm{e}} \frac{G_{\infty}^{\prime}}{G_{\min }^{\prime \prime}}
$$

where $l_{\mathrm{e}}$ is the average length between two entanglement points and $G_{\min }^{\prime \prime}$, the minimum value of loss modulus at high-frequency region. Though the $l_{\mathrm{e}}$ is not currently available, however, as a comparison, a typical value of $l_{\mathrm{e}}(80-150 \mathrm{~nm})$ for worm-like micelles can be adopted ${ }^{38}$ and thus $L$ of the worm-like micelle formed by SHS/Bola4 corresponds to roughly 230-430 $\mathrm{nm}$.
This is longer than those formed by SDES in the presence of $\mathrm{AlCl}_{3}$ or $\mathrm{CaCl}_{2}$, the values are 100-200 nm (the longest $\sim 400$ $\mathrm{nm}$ ) for SDES/ $\mathrm{AlCl}_{3}{ }^{14(a, b)}$ and 50-200 nm (the longest $\sim 300$ $\mathrm{nm}$ ) for SDES/CaCl $2 .{ }^{14 \mathrm{~d}}$ Since the viscosity of SHS/Bola2Et is far higher than that of SHS/Bola4, the average length of SHS/ Bola2Et micelle should be longer than that of SHS/Bola4.

\section{Conclusions}

In this paper, we report the viscoelastic worm-like micelle systems formed by mixing traditional single-head and singlechain anionic surfactant, SHS, and a bolaform salt, Bola2Et or Bola4. Both Bola2Et and Bola4 have a short spacer between the charged headgroups. By electrostatic attraction, the complex molecules made up of two SHS and one Bola-counterion are induced and the effective molecule geometry in the aggregate becomes columnar-like. This favors the formation of long worm-like micelles and thus the solution produces excellent viscoelaticity. The present results suggest an approach to construct highly viscoelatic anionic worm-like micellar systems, i.e., inducing single-chain surfactants into pseudo gemini structure complexes with a columnar-like geometry by suitable Bolacounterions in the solution.

\section{References}

(1) Dreiss, C. A. Soft Matter 2007, 3, 956 and references therein.

(2) Ezrahi, S.; Tuval, E.; Aserin, A. Adv. Colloid Interface Sci. 2006, $128-130,77$ and references therein.

(3) Trickett, K.; Eastoe, J. Adv. Colloid Interface Sci. 2008, 144, 66 and references therein.

(4) Shikata, T.; Hirata, H. Langmuir 1987, 3, 1081.

(5) Shikata, T.; Hirata, H.; Kotaka, T. Langmuir 1988, 4, 354.

(6) Makhloufi, R.; Hirsch, E.; Candau, S. J.; Binana-Limbele, W.; Zana, R. J. Phys. Chem. 1989, 93, 8095.

(7) Ali, A. A.; Makhloufi, R. Phys. Rev. E 1997, 56, 4474.

(8) Ali, A. A.; Makhloufi, R. Colloid Polym. Sci. 1999, 277, 270.

(9) Clausen, T. M.; Vinson, P. K.; Minter, J. R.; Davis, H. T.; Talmon, Y.; Miller, W. G. J. Phys. Chem. 1992, 96, 474.

(10) Aswal, V. K.; Goyal, P. S.; Thiyagarajan, P. J. Phys. Chem. B 1998, 102, 2469.

(11) Soltero, J. F. A.; Puig, J. E.; Manero, O. Langmuir 1996, 12, 2654.

(12) Maitland, G. C. Curr. Opin. Colloid Interface Sci. 2000, 5, 301.

(13) (a) Magid, L. J.; Li, Z.; Butler, P. D. Langmuir 2000, 16, 10028. (b) Arleth, L.; Bergström, M.; Pedersen, J. S. Langmuir 2002, 18,5343 .

(14) (a) Mu, J. H.; Li, G. Z. Colloid Polym. Sci. 2001, 279, 872. (b) Mu, J. H.; Li, G. Z.; Wang, Z. W. Rheol. Acta 2002, 41, 493. (c) Mu, J. H.; Li, G. Z.; Jia, X. L.; Wang, H. X.; Zhang, G. Y. J. Phys. Chem. B 2002, 106, 11685.

(d) Mu, J. H.; Li, G. Z. Chem. Phys. Lett. 2001, 345, 100.

(15) Kalur, G. C.; Raghavan, S. R. J. Phys. Chem. B 2005, 109, 8599. 
(16) Menger, F. M.; Littau, C. A. J. Am. Chem. Soc. 1993, 113, 1451.

(17) Kern, F.; Lequeux, F.; Zana, R.; Candau, S. J. Langmuir 1994, 10, 1714 .

(18) Danino, D.; Talmon, Y.; Zana, R. Langmuir 1995, 11, 1448.

(19) Oda, R.; Huc, I.; Homo, J. C.; Heinrich, B.; Schmutz, M.; Candau, S. Langmuir 1999, 15, 2384.

(20) Moroi, Y.; Matuura, R.; Kuwamura, T.; Inokuma, S. J. Colloid Interface Sci. 1986, 113, 225.

(21) Moroi, Y.; Murata, Y.; Fukuda, Y.; Kido, Y.; Seto, W.; Tanaka, M. J. Phys. Chem. 1992, 96, 8610.

(22) Moroi, Y.; Matuura, R.; Tanaka, M.; Murata, Y.; Aikawa, Y.; Furutani, E.; Kuwamura, T.; Takahashi, H.; Inokuma, S. J. Phys. Chem. 1990, 94, 842.

(23) Yang, D. P.; Zhao, J. X. Colloids Surf. A accepted.

(24) Nlshikldo, N.; Kobayashl, H.; Tanaka, M. J. Phys. Chem. 1982, 86,3170 .

(25) Shrestha, R. G.; Shrestha, L. K.; Aramaki, K. J. Colloid Interface Sci. 2007, 311, 276.

(26) Pei, X. M.; Zhao, J. X.; Ye, Y. Z.; You, Y.; Wei, X. L. Soft Matter 2011, 7, 2953.
(27) Pei, X. M.; Zhao, J. X.; Wei, X. L. J. Colloid Interface Sci. 2011, 356, 176

(28) Raghavan, S. R.; Kaler, E. W. Langmuir 2001, 17, 300.

(29) Israelachvili, J. Intermolecular \& Surface Forces, 2nd ed.; Academic Press: San Diego, 1992; pp 370-382.

(30) Alami, E.; Beinert, G.; Marie, P.; Zana, R. Langmuir 1993, 9, 1465.

(31) Wettig, S. D.; Verrall, R. E. J. Colloid Interface Sci. 2001, 235, 310 .

(32) Tanford, C. J. Phys. Chem. 1972, 76, 3020.

(33) Granek, R.; Cates, M. E. J. Chem. Phys. 1992, 96, 4758.

(34) Cates, M. E. Macromolecules 1987, 20, 2289.

(35) Khatory, A.; Lequeux, F.; Kern, F.; Candau, S. J. Langumir 1993, 9, 1456.

(36) Oda, R.; Narayanan, J.; Hassan, P. A.; Manohar, C.; Salkar, R. A.; Kern, F.; Candau, S. J. Langmuir 1998, 14, 4364.

(37) Granek, R.; Cates, M. E. J. Chem. Phys. 1992, 96, 4758.

(38) Acharya, D. P.; Kunieda, H.; Shiba, Y.; Aratani, K. J. Phys. Chem. B 2004, 108, 1790. 